\title{
Study on Strongyle Infection of Donkeys and Horses in Hosaena District, Southern Ethiopia
}

This article was published in the following Dove Press journal:

Veterinary Medicine: Research and Reports

\section{Mesfin Mathewos (D) \\ Haben Fesseha $\mathbb{D}^{2}$ \\ Metages Yirgalem ${ }^{3}$}

'Department of Veterinary Pathology, Wolaita Sodo University, School of Veterinary Medicine, Wolaita Sodo, Ethiopia; ${ }^{2}$ Department of Veterinary Surgery and Diagnostic Imaging, Wolaita Sodo University, School of Veterinary Medicine, Wolaita Sodo, Ethiopia; ${ }^{3}$ Department of Veterinary Microbiology, Haramaya University, College of Veterinary Medicine, Harari, Ethiopia

Correspondence: Mesfin Mathewos Email mathewosme23@gmail.com
Introduction: Gastrointestinal helminth parasite infection is a major influencing factor against the profitability of working equines all over the world.

Methods: This cross-sectional study was conducted in the Hosaena district to investigate the prevalence and the potential risk factors of strongyle infection. To address this, 384 equines; donkeys $(n=208)$, and horses $(n=176)$ were randomly selected for the coprological examination to identify strongyle eggs using the floatation technique.

Results: The study revealed that the overall prevalence of strongyle infection in the Hosaena district was $54.2 \%$ and the respective prevalence was $59.1 \%$ and $48.2 .0 \%$ in donkeys and horses, respectively. Strongyles' infection rates in equines were $56.3 \%, 53.2 \%$, and $56.6 \%$ in young, adult, and old animals, respectively, while the rates were $52.8 \%$ and $57.1 \%$ in male and female animals. Equids with a good body condition were highly prone to strongyle infection than equines with poor and medium body condition, and equids used for transport and packing, cart pulling, and no purpose were highly infected than those used for packing and transport purposes. A significant variation $(\mathrm{P}<0.05)$ was shown in the statistical analysis between the equines and the prevalence of strongyle infection. However, the occurrence of strongyle infection was not significantly $(\mathrm{P}>0.05)$ associated with age, sex, and body condition score of equines.

Conclusion: Hence, strongyles infection is widely distributed in equines in the study area. Further research, including broad sample sizes of gastrointestinal nematodes in all equines, should therefore be recommended for strategic prevention and control measures in order to understand the severity of the disease.

Keywords: Donkeys, Horses, Hosaena, Prevalence, Strongyles

\section{Introduction}

Ethiopia is one of the developing countries of Africa, which is predominantly an agricultural country with more than $85 \%$ of its population engaged in farming activities. ${ }^{1}$ The country has numerous agro-ecological zones that have contributed to the growth of different systems of agricultural production. ${ }^{2}$ The total world equines population is estimated at approximately 112.5 million (58.5 million horses, 43.3 million donkeys, and 10.5 million mules). ${ }^{3,4}$ Ethiopia owns approximately 1.91 million horses, 6.75 million donkeys, and 0.35 million mules, according to the central statistical agency. ${ }^{4}$

Equines play an important role in the livelihoods of millions of people worldwide, as well as being used in agricultural and tourism activities for the loading, traveling, carting, plowing, and transport of goods, people, and building materials. $^{5,6}$ While equines are often characterized as hardy and resistant, they suffer from many health problems. ${ }^{7}$ Despite its huge population size, due to the 
high prevalence of malnutrition, management limitations, and disease like a parasite, the equines remain marginal. Parasitism is a major barrier to the growth of the livestock farming system in the country ${ }^{8}$ and is characterized by high morbidity and mortality rates. Severe health threats are gastrointestinal nematodes, which lead to poor body condition, reduced power production, poor productive performance, and short life span. ${ }^{8,9}$ Among GIT nematodes, the Strongylidae family, commonly referred to as Strongyles, is a serious obstacle to effective equines management due to animal weakness and death, particularly when heavy burdens are involved. ${ }^{4}$

Clinically infected equines exhibit signs of unthriftiness, anemia, pruritis, colic, and diarrhea. ${ }^{10-12}$ Most intestinal equines nematodes can be diagnosed by the demonstration of parasite eggs from faecal samples. ${ }^{9,11}$ Although considerable work has been carried out on equines strongyle infection in various parts of Ethiopia by, ${ }^{4,13-18}$ and showed an infection rate of $5.73 \%$ in Dangila Town, 64.61\% in Menz Keya Gerbil District, 26.56 in Jimma district, 46.1\% in Batu Town, 63\% in Mecha district, 83.85\% in Bahirdar district and $72.25 \%$ in Jimma Town, respectively. However, there was no previous study carried out on the strongyle infection of donkeys and horses in the present study area, where a mixed crop-livestock production system is the main form of agriculture. On the other hand, knowing the current situation of strongyle infection in the area could be the basis for all possible actions including its control and prevention. Therefore, this study was conducted to determine the prevalence and potential risk factors of strongyle infection in equines of Hosaena district, Southern Ethiopia.

\section{Materials and Methods Study Area}

This study was carried out in Hosaena district, the capital of the Hadiya zone in Southern Nations, Nationalities, and People's Regional State, Ethiopia, from October 2019 to June 2020. Hosaena, located $232 \mathrm{~km}$ from Addis Ababa and $168 \mathrm{~km}$ from Hawassa, the regional capital, is the administrative center of the Hadiya zone. It has a latitude and longitude of $7^{\circ} 33 \mathrm{~N}$ and $37^{\circ} 51^{\prime} \mathrm{E}$, with an altitude of 2177 meters above sea level, respectively. The average mean temperature and precipitation are $16.9^{\circ} \mathrm{C}$ and $1071 \mathrm{~mm}$ respectively. The region exhibits a system of bimodal rainfall (long and short rainy seasons). The region shows a system of bimodal rainfall (long and short rainy seasons). The long rainy season runs between June and September, while the short rainy season runs from midFebruary to late April. ${ }^{19}$

\section{Study Animals}

The study animals were 384 indigenous breeds of horses $(n=176)$ and donkeys $(n=208)$ kept mainly for traction power and packing, transport, and cart pulling in and around Hosaena, Hadiya district, Southern Regional State, by various peasant associations. Horses and donkeys of all age groups, both sexes, and held under extensive management systems were included in this research. The study equines were commonly fed on a free grazing system which makes it difficult to control the parasite in the study area. Even though there was deworming of equines provided by government community service program by Anthelmintics, its coverage was limited. The dentition pattern was characterized by the age of the selected animals as described by McLean ${ }^{20}$ and grouped as young ( $<5$ years), adult (5-10 years), and old ( $>10$ years). Body condition scoring (BCS) of the donkeys was estimated based on the guides described by. ${ }^{21}$

\section{Study Design and Sampling Techniques}

A cross-sectional study design was used to determine the prevalence and associated risk factors of strongyle infection of donkeys and horses in the study area. A simple random sampling technique was used to select study animals. The sample size was determined using the formula given by Thrusfield, ${ }^{22}$ with $50 \%$ expected prevalence; a $5 \%$ desired absolute precision, and a 95\% confidence interval. Therefore, 384 equines would be obtained for the study using the formula.

$$
\mathrm{n}=\frac{1.96 P \exp (1-\mathrm{Pexp})^{2}}{\mathrm{~d}^{2}}
$$

Where $\mathrm{n}=$ required sample size, Pexp $=$ expected prevalence of nematode parasites $(\mathrm{P}=50 \%), \mathrm{Z}=1.96$ for $95 \%$ confidence interval and $\mathrm{D}=$ desired absolute precision.

\section{Study Methodology}

\section{Sampling and Coprological Examination}

A total of 384 faecal samples were collected from donkeys and horses in the study area between October 2019 to June 2020. Donkeys and horses were restrained for sample collection. After restraining, approximately about 3 grams of faecal sample were collected directly from the rectum and or from recently defecated faeces (within the last 10 minutes prior to collection in the houses) using gloved hands. Each 
sample was labeled with identification of the animal (sex, age, BCS, and name of the owner) and then transported in a cool box to the Sodo regional veterinary laboratory, department of Veterinary parasitology and stored at $4^{\circ} \mathrm{C}$ until coprological analysis. All fecal samples were then subjected to flotation analysis using the modified McMaster method to determine the eggs of strongyles in equines. ${ }^{23}$

Moreover, the donkeys were classified into different levels based on strongyle egg shedding or egg per gram of feces (EPG) according to the guidelines of Nielsen et $\mathrm{al}^{24}$ and Kaplan and Nielsen. ${ }^{25}$ Accordingly, the donkeys are categorized into mild if the egg count level is within the range of 0-200 EPG, moderate if the egg count level is 200-500 EPG, and severe if the egg count level is greater than $500 \mathrm{EPG}$.

\section{Data Management and Statistical Analysis}

The data obtained from the study area were entered into the Microsoft Excel 2010 spreadsheet and were correctly coded and analyzed using statistical software STATA version $13 .{ }^{26}$ The descriptive statistics were analyzed and described as percentages and frequencies. To compare and measure the relationship between the prevalence of strongyle infections and possible risk factors, the chi-square test was used. Logistic regression (reporting odds ratio) was also used to see the effects of strongyle infection on individual possible risk factors. Variables with a significant odds ratio (OR) value was considered to have an association at a $95 \%$ confidence interval and the level of significance was considered when $\mathrm{p}$ is less than 0.05 .

\section{Ethical Clearance}

The best practice guidelines for veterinary care were followed and those equine owners were informed as to the purpose of the study, and that the Wolaita Sodo University of Research Ethics and Review Committee approved the verbally informed consent process in the manuscript.

\section{Results \\ Overall Occurrence of Strongyles in Equines}

From a total of 384 faecal samples examined, $54.2 \%$ (208/384) of the equines were positive for one or more eggs of strongyle nematodes of equids. The prevalence of gastrointestinal strongyles was higher in donkey 59.1\% (123/208) than horse $48.2 \%(83 / 176)$, and there was a statistically significant difference $\left(\mathrm{X}^{2}=4.51 ; \mathrm{p}=0.034\right)$ between Equines and the occurrence of strongyle infection (Figure 1).

\section{Prevalence of Strongyle Infection with Their Potential Risk Factors in Equines}

As indicated in Table 1, there was no statistically significant association $(p<0.05)$ between the occurrence and potential risk factors such as sex, age, body condition score, and purpose of Equines. Sex-wise prevalence revealed that female $(57.1 \%)$ equines were more susceptible to gastrointestinal strongyles infection than female (52.8\%) one. Older equines $(56.6 \%)$ were more susceptible to strongyle infection as compared to young (56.3\%) and adults (53.2\%). Equines with a good body condition score (57.8\%) were more prone to strongyle infection as compared to medium (50.4\%) and good body condition score (53.9\%).

Equines which were used for transport and packing purpose revealed a prevalence of $64.2 \%$ followed by cart pulling (57.1\%), no purpose (56.9\%), transport (54.5\%), and packing (49.7\%). The odds of young Equines infected by strongyle

\section{Prevalence of Strongyle Infection (\%)}

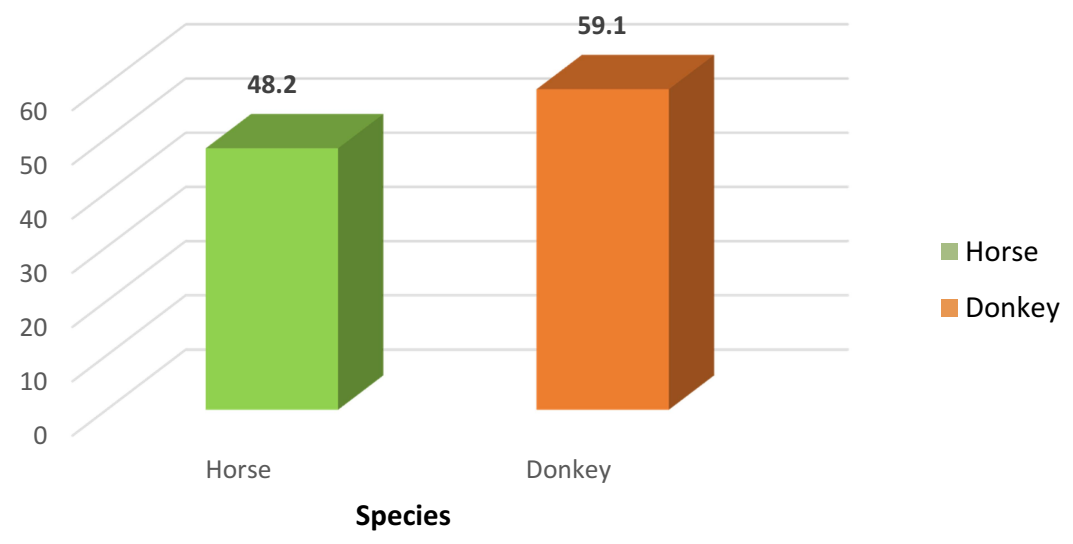

Figure I Prevalence of strongyle infection with regard to species. 
Table I Prevalence of Strongyle Infection Regarding Potential Risk Factors

\begin{tabular}{|c|c|c|c|c|c|c|c|}
\hline Risk Factors & No. of Examined & No. of Positive & Prevalence & OR & 95\% Cl (Lower-Upper) & $x^{2}$ & P-value \\
\hline \multicolumn{8}{|l|}{ Sex } \\
\hline Male & 263 & 139 & 52.8 & 0.970 & $0.615-1.52$ & $0.58 \mathrm{I}$ & 0.446 \\
\hline Female & 121 & 69 & 57.1 & Ref & Ref & & \\
\hline \multicolumn{8}{|l|}{ Age } \\
\hline Young & 87 & 49 & 56.3 & 1.06 & $0.583-1.95$ & 0.342 & 0.843 \\
\hline Adult & 267 & 142 & 53.2 & Ref & Ref & & \\
\hline Old & 30 & 17 & 56.6 & 0.896 & $0.274-2.92$ & & \\
\hline \multicolumn{8}{|l|}{ Body condition } \\
\hline Good & 114 & 66 & 57.8 & Ref & Ref & 1.23 & 0.541 \\
\hline Medium & 107 & 54 & 50.4 & 0.803 & $0.391-1.64$ & & \\
\hline Poor & 88 & 163 & 53.9 & 0.889 & $0.45 \mathrm{I}-1.75$ & & \\
\hline \multicolumn{8}{|l|}{ Purpose } \\
\hline Transport and packing & 42 & 27 & 64.2 & 1.58 & $0.589-4.23$ & 3.49 & 0.479 \\
\hline Transport & 55 & 30 & 54.5 & 1.07 & $0.366-3.13$ & & \\
\hline Packing & 173 & 86 & 49.7 & 1.03 & $0.355-3.01$ & & \\
\hline No purpose & 79 & 45 & 56.9 & 0.997 & $0.345-2.87$ & & \\
\hline Cart pulling & 35 & 20 & 57.1 & Ref & Ref & & \\
\hline
\end{tabular}

infection were 1.06 times higher (CI, 0.583-1.95) than old equines (CI, 0.274-2.92) while adult animals were kept constant. Whereas the odds of Equines used for transport and packing, transport, and packing purpose infected by strongyle infection were 1.58 (CI, 0.589-4.23), 1.07 (CI, 0.366-3.13), and 1.03 (CI, 0.355-3.01) times higher than Equines used for no purpose while cart pulling Equines was held constant (Table 1).

\section{Level of Strongyle Infection in Equines}

According to the present study, the degree of infection of strongyles as indicated by EPG revealed that $70.2 \%$ of the equines were infected with a severe degree of strongyle infection, while $25.9 \%$ of the equines harbored a moderate level of strongyle infection and a mild degree of infection was recorded in $3.85 \%$ of equines of the study sites. The level of infection has a statistically significant association $\left(\mathrm{X}^{2}=353.17, \mathrm{p} \leq 0.0001\right)$ with the occurrence of strongyle infection (Table 2).

Table 2 Prevalence of Helminth Infestation in Donkeys of the Study Areas

\begin{tabular}{|l|l|l|l|l|l|}
\hline \multirow{2}{*}{$\begin{array}{l}\text { Egg per } \\
\text { Gram of } \\
\text { Faeces (EPG) }\end{array}$} & \multicolumn{3}{|l|}{ Degree of Infection (\%) } & \multirow{2}{*}{$\mathbf{X}^{2}$} & \multirow{2}{*}{-value } \\
\cline { 2 - 4 } & Mild & Moderate & Severe & & \\
\hline Strongyle egg & $8(3.85)$ & $54(25.9)$ & $146(70.2)$ & 353.17 & 0.0001 \\
\hline
\end{tabular}

\section{Discussion}

Nematode parasites are extreme Equines health hazards, leading to poor body condition, decreased power production, poor reproductive potential, retarded growth, and short Equines life. This study revealed a slightly higher $54.2 \%$ prevalence of gastrointestinal strongyle infection, which is comparatively lower compared to other studies performed at different geographical locations, which indicated a prevalence of $63 \%, 63.25 \%, 64 \%, 64.61 \%$, $83.85 \%, 99.15 \%$ and $100 \%, 9,14,16-18,27-30$ respectively. This variance may be due to the difference in the region's agro-ecology and Equines population density, and the tradition of using Equines anthelmintic therapy in the study area. However, compared to, ${ }^{4,13,15}$ the present result showed a higher overall prevalence, which registered an infection rate of $5.73 \%, 26.56 \%$, and $46.1 \%$, respectively.

In the current report, the prevalence of gastrointestinal strongyles in donkeys and horses was $59.1 \%$ and $48.2 \%$, respectively. This study revealed a statistically significant difference $(\mathrm{P}<0.05)$ between equines and gastrointestinal strongyles infection. The results of the current study disagreed with the previous reports of Ayele and Dinka, 2010, Ayele et al, 2006, Mezgebu et al, 2013, Bogale et al, 2012, Tedla and Abichu, 2018, Tesfu et al, 2014 $1,9,17,31-33$ who reported a prevalence of $93 \%$ in Bereh, $87 \%$ in Boset and $95 \%$ in Adaa; 87\%, 87.7\%, 88.21\%, 82.75\%, 79.31\% and $64.9 \%$ in donkeys, respectively. As compared to the finding 
of the present study, Saeed et al, 2010, Cirak et al, 2005, Tedla and Abichu, 2018, Mezgebu et al, 2013, Tesfu et al, $2014^{9,10,32-34}$ reported a higher prevalence of strongyle infection in horses with an infection rate of $58.50 \%, 68 \%$, $63.72 \%, 66.5 \%$, and $76 \%$, respectively. This difference could be due to the variation in environmental conditions, sample size, sampling time, parasite larvae survival management practice, and the accessibility of anthelmintics in the study area. The present study, on the other hand, agreed with the reports of Addis et $\mathrm{al}^{16}$ who demonstrated an infection rate of $60.6 \%$ in donkeys. Reinemeyer et $\mathrm{al}^{35}$ reported that, an overall prevalence of small strongyles is high in horses and that $100 \%$ of horses are infected with these parasites. ${ }^{35}$ Khallaayoune, $^{36}$ showed, however, that donkeys were severely infected with helminth parasites in Morocco, including Trichostrongylus axei in the stomach, $S$. vulgaris, $S$. edentatus, and small strongyles in the large intestines that agreed with the present finding showed a high prevalence of strongyle infection in donkeys rather than horses. ${ }^{36}$

In this study, the occurrence of strongyles infection was not showed a statistically significant difference with sex and age groups of equines. This finding agreed with previous reports of Saeed et al and Bogale et al. ${ }^{10,17}$ The prevalence of strongyles infection in female and male equids were $57.1 \%$ and $52.8 \%$, respectively. This higher prevalence of infection with strongyle nematode in female equids may be attributed to a higher chance of obtaining grazing pasture feeds compared to males, so females are mainly used for breeding and were thus kept in the field most of the days. Male was, however, used for the purpose of carting pulling, so the owners of equids feed them concentrate feeds rather than roughage. For young, adult, and old equines, the age-related infection rate was $56.3 \%, 53.2 \%$, and $56.6 \%$. The higher prevalence of strongyle infection in old Equines in the current study disagreed with Beaver, ${ }^{37}$ who documented a higher prevalence of strongyle infection in young animals than in adult and old equines. This may be due to the disparity between the three age groups in the animal's immune condition, management, nutrition, and practice of deworming.

In the present study, there was no statistically significant difference $(\mathrm{P}>0.05)$ between the body condition score of equines and the occurrence of strongyle infection. A similar finding was reported by Bogale et al. ${ }^{17}$ On the other hand, this finding disagreed with the previous reports by $^{1,9,38}$ who reported a statistically significant association between the existence of strongyle infection with the body condition score of equines.

In addition, there was no statistically significant difference $(\mathrm{P}>0.05)$ between equines held for various purposes and infection with strongyles. Addis et al, ${ }^{16}$ who reported a substantial association of strongyle infection among equines held for various purposes, disagreed with this report. Equines used for transport and packing, cart pulling and no purpose were discovered in Mecha Woreda with a higher prevalence of strongyles infection than animals used for packing and transport, which agreed with previous studies (Addis et al, 2017). Perhaps this is due to the differences in management provided to these animal groups and the practice of providing special treatment for packing and transport in a confined area, such as deworming and feeding with concentrates, which may decrease the probability of gastrointestinal strongyle infection compared to equid held for packing and transport, cart pulling and no purpose.

In the current study, $70.2 \%$ of the equines were infected with a severe degree of strongyle infection, while $25.9 \%$ of the equines harbored a moderate level of strongyle infection and a mild degree of infection was recorded in $3.85 \%$ of equines of the study sites. This observation was comparable with the previous report by Fesseha et $\mathrm{al}^{39}$ in Hosaena who reported an EPG of $73 \%$, $23.9 \%$, and $3.04 \%$ of a severe, moderate, and a mild degree of strongyle infection in donkeys, respectively. Hutchison and Mfitlidoze ${ }^{40}$ in Australia, also reported $80 \%$ of horses were infected with gastrointestinal parasites. This study has shown that strongyles are highly prevalent in Equines residing in study areas since all $(100 \%)$ of the donkeys exceeded the cutoff value (200 EPG). One of the basic principles of selective anthelmintic treatment is a consistency of the relative magnitude of strongyle Faecal egg counts of individual donkeys over time. $^{41}$

\section{Conclusion}

The prevalence of gastrointestinal strongyles in the equines in the current study area was generally high. However, the findings of strongyle in equines warrant the need for the adoption of control and prevention measures because these parasites can interfere with growth and reduced productivity. This study also identified sex, age, body condition, and purpose of equines as a potential risk factor for the occurrence of GIT strongyles in equines though they were not statistically significant $(\mathrm{p}>0.05)$. 
Thus, further research including large samples of gastrointestinal nematodes, prevention, and control of worms with a significant improvement in nutrition and management should be established to combat the effects of strongyles infection in equines.

\section{Abbreviations}

BCS, Body condition Score; EPG, Egg per gram of faeces; GIT, Gastrointestinal tract; Ref, Reference category.

\section{Data Sharing Statement}

The datasets used and analyzed during the current study are available from the corresponding author on reasonable request.

\section{Ethics Approval and Consent to Participate}

The Wolaita Sodo University of Research Ethics and Review Committee provided ethical approval for this research. Before collecting samples, verbal consent was also sought from the equine owners to take samples from their equine and then, while taking faecal samples from the rectum, adopted strict hygienic measures. The best practice guidelines for veterinary care were followed and those equine owners were informed as to the purpose of the study, and that the Wolaita Sodo University of Research Ethics and Review Committee approved the verbally informed consent process in the manuscript.

\section{Acknowledgments}

The authors would like to acknowledge the regional veterinary laboratory of Sodo.

\section{Author Contributions}

All authors made substantial contributions to conception and design, acquisition of data, or analysis and interpretation of data; took part in drafting the article or revising it critically for important intellectual content; agreed to submit to the current journal; gave final approval of the version to be published; and agree to be accountable for all aspects of the work.

\section{Disclosure}

All authors declared no competing conflicts of interest in this work.

\section{References}

1. Ayele G, Feseha G, Bojia E, Joe A. Prevalence of gastro-intestinal parasites of donkeys in Dugda Bora District, Ethiopia. Livestock Res Rural Develop. 2006;18(10):14-21.

2. Tegegne A, Crawford T. Draft animal power use in Ethiopia. Draft Animal News. 2000;33.

3. Abdela N, Teshome E, Hassan A, Deressa FB. Prevalence and associated risk factors of Equine wound in and around Asella town, South Eastern Ethiopia. J Veterinary Med Anim Health. 2017;9(4):63-71.

4. Mangassa B, Tafese W. Prevalence of strongyle infection and associated risk factors in horse and donkeys in and around Batu Town, East Shoa, Oromia Regional State, Ethiopia. Food Sci Qual Manage. 2016;54.

5. Pritchard JC. Animal traction and transport in the 21 st century: getting the priorities right. Veterinary J. 2010;3(186):271-274.

6. Wubishet Z, Yacob H. Cross-sectional survey on equine gastro intestinal stroglylosis and fasciolosis in Goba District of Bale Zone, Oromia Regional State, Ethiopia. Anim Vet Sci. 2017;5(5):84-88.

7. Takele B, Nibret E. Prevalence of gastrointestinal helminthes of donkeys and mules in and around Bahir Dar, Ethiopia. Ethiop Veterinary J. 2013;17(1):13-30.

8. Wondimu A, Sharew G. Gastrointestinal nematodes of donkeys and horses in Gondar town northwest, Ethiopia. $J$ Veterinary Med Anim Health. 2017;9(5):88-91.

9. Tedla M, Abichu B. Cross-sectional study on gastro-intestinal parasites of equids in South-western Ethiopia. Parasite Epidemiol Control. 2018;3(4):e00076.

10. Saeed K, Qadir Z, Ashraf K, Ahmad N. Role of intrinsic and extrinsic epidemiological factors on strongylosis in horses. J Anim Plant Sci. 2010;20(4):277-280.

11. Foreyt WJ. Veterinary Parasitology Reference Manual. John Wiley \& Sons; 2013.

12. Zajac AM, Conboy GA. Veterinary Clinical Parasitology. John Wiley \& Sons; 2012.

13. Haimanot D, Alebachew A, Zenebe T, Kebede G. Prevalence of strongyle infection in horses and donkeys in and around Dangila town, northwest Ethiopia. Acta Parasitol Glob. 2015;6(1):14-19.

14. Molla B, Worku Y, Shewaye A, Mamo A. Prevalence of strongyle infection and associated risk factors in equine in Menz Keya Gerbil District, North-Eastern Ethiopia. J Veterinary Med Anim Health. 2015;7(4):117-121.

15. Sori G, Bekele T, Geso G, et al. Prevalence of equine strongyle infection and its associated risk factors in Jimma Town, Southwest Ethiopia. Int J Livestock Prod. 2017;8(11):187-191.

16. Addis $\mathrm{H}$, et al. Cross-sectional study on the prevalence of equine strongyle infection Inmecha Woreda, Ethiopia. Int J Adv Res Biol Sci. 2017;4(8):68-77.

17. Bogale B, Sisay Z, Chanie M. Strongyle nematode infections of donkeys and mules in and around Bahirdar, Northwest Ethiopia. Global Veterinaria. 2012;9(4):497-501.

18. Andarge B, Muhammed C, Tibesso G. Prevalence of Major Intestinal Nematodes of Equines In Jimma Town, South-Western Ethiopia. Int J Vet Sci Res. 2017;3(2):069-073.

19. Sedoro T, Ejajo T, Abute L, Kedir T, Erchafo B. Process evaluation of skilled delivery service in Hadiya Zone in Southern Nations, nationalities, and peoples region, Ethiopia. J Environ Public Health. 2020;2020.

20. McLean AK, Improving donkey (Equus asinus) welfare through enhanced management, training, and education. Ph.D. thesis, Michigan State University. 2010.

21. Svendsen E. The Professional Handbook of the Donkey. Donkey Sanctuary (Salcombe Regis, England); 1989.

22. Thrusfield M. Veterinary Epidemiology. John Wiley \& Sons.; 2018.

23. Hendrix CM, Robinson E. Diagnostic Parasitology for Veterinary Technicians-E-Book. Elsevier Health Sciences; 2016. 
24. Nielsen M, Haaning N, Olsen S. Strongyle egg shedding consistency in horses on farms using selective therapy in Denmark. Vet Parasitol. 2006;135(3-4):333-335.

25. Kaplan R, Nielsen M. An evidence-based approach to equine parasite control: it ain't the 60s anymore. Equine Vet Educ. 2010;22(6):306-316.

26. StataCorp, L. Stata Statistical Software: Release 13; 2013.

27. Sotiraki S, Badouvas A, Himonas C. A survey on the prevalence of internal parasites of equines in Macedonia and Thessalia-Greece. $J$ Equine Veterinary Sci. 1997;17(10):550-552.

28. Zerihun A, Bersissa K, Bojia E, Ayele G, Tesfaye M, Etana D. Endoparasites of donkeys in Sululta and Gefersa districts of central Oromia, Ethiopia. J Anim Vet Advan. 2011;10(14):1850-1854.

29. Seri H, et al. A survey of gastrointestinal nematodes of donkeys (Equus asinus) in Khartoum State, Sudan. J Anim Vet Advan. 2004.

30. Belay M. Preliminary Study on Helmenthosis of Equines in South and North Wollo Zones. Kombolcha Regional Veterinary Laboratory. Ethiopia: Kombolcha; 2011.

31. Ayele G, Dinka A. Study on strongyles and parascaris parasites population in working donkeys of central Shoa, Ethiopia. Livest Res Rural Dev. 2010;22(12):1-5.

32. Mezgebu T, Tafess K, Tamiru F. Prevalence of gastrointestinal parasites of horses and donkeys in and around Gondar Town, Ethiopia. Open J Veterinary Med. 2013;3(06):267.

33. Tesfu N, Asrade B, Abebe R, Kasaye S. Prevalence and risk factors of gastrointestinal nematode parasites of horse and donkeys in Hawassa town, Ethiopia. J Veterinary Sci Technol. 2014;5 (5):2157-7579
34. Cirak VY, Güleğen E, Bauer C. The prevalence of strongyle infections and persistent efficacy of pyrantel embonate, ivermectin, and moxidectin in Turkish horses. Turkish J Veterinary Anim Sci. 2005;29 (1):175-181.

35. Reinemeyer $\mathrm{C}$, et al. The prevalence and intensity of internal parasites of horses in the USA. Vet Parasitol. 1984;15(1):75-83.

36. Khallaayoune K. Benefit of a Strategic Deworming Programme in Working Donkeys in Morocco. In Donkeys, Mules \& Horses in Tropical Agricultural Development: Proc of a Colloquium Organ by the Edinburgh School of Agric \& the Cent for Trop Vet Med of the Univ of Edinburgh \& Held in Edinburgh, Scotland, 3rd-6th Sept 1990. Edinburgh: Centre for Tropical Veterinary Medicine; 1991.

37. Beaver PC. Helminths, Arthropods, and Protozoa of domesticated animals. Am J Trop Med Hyg. 1983;32(4):906.

38. Shiferaw Y, Gebreab F, Wesene A. Survey on helmenthosis of equines in Wonchi, 2001. J Ethiop Vet Assoc. 2001;5(1).

39. Fesseha H, Mathewos M, Kidanemariam F. Anthelmintic Efficacy of Strongyle Nematodes to Ivermectin and Fenbendazole on Working Donkeys (Equus asinus) in and around Hosaena Town, Southern Ethiopia. Vet Med Int. 2020;2020.

40. Waller W, Mfitlidoze S. Prevalence of GIT nematodes in Australian horses. e-J Parasitol. 1989;64:104-105.

41. Duncan J, Love S. Preliminary observations on an alternative strategy for the control of horse strongyles. Equine Vet J. 1991;23 (3):226-228.

\section{Publish your work in this journal}

Veterinary Medicine: Research and Reports is an international, peerreviewed, open access journal publishing original research, case reports, editorials, reviews and commentaries on all areas of veterinary medicine. The manuscript management system is completely online and includes a very quick and fair peer-review system. Visit $\mathrm{http}: / / \mathrm{www}$. dovepress.com/testimonials.php to read real quotes from published authors.

Submit your manuscript here: http://www.dovepress.com/veterinary-medicine-research-and-reports-journal 